\title{
Reflejos y reverberaciones de la guerra en la obra de Mircea Eliade: La Noche de San Juan y Doce mil cabezas de ganado
}

\author{
Adrian DAMŞESCU \\ Departamento de Lingüística Teórica y Aplicada \\ Universidad Transilvania de Braşov \\ adrian.damsescu@unitbv.ro
}

\begin{abstract}
RESUMEN
El propósito de este artículo es el de poner de relieve aspectos relacionadas con la Segunda Guerra Mundial en la obra literaria del escritor rumano Mircea Eliade, con especial hincapié en las dos obras del título, al contener estas el tema estudiado. Son creaciones de estilo diferente, la primera una novela épica de grandes dimensiones redactada en estilo realista, de tipo documental (al tener como fundamento acontecimientos autobiográficos), aunque con frecuentes incursiones en lo mítico, mientras la segunda es un relato fantástico de apenas unas páginas; lo que las une es la descripción del atroz bombardeo americano sobre Bucarest del Domingo de Pascua del año 1944. A este trágico acontecimiento se han referido también otros autores, como el escritor contemporáneo Gabriel Stan en su libro El Quinto Mosquetero, quien lo describe de forma muy plástica en unos párrafos que he incorporado parcialmente al final del artículo.
\end{abstract}

Palabras clave: literatura, guerra, Mircea Eliade, La Noche de San Juan, Doce mil cabezas de ganado, Gabriel Stan.

\section{Reflexions and reverbarations of the war in the literary work of Mircea Eliade: The Forbidden Forest and Twelve Thousand Head of Cattle}

\begin{abstract}
As the tittle hints, the article is about World War Two aspects presents in the two literary works of the tittle, since the theme of the war is very present in both. They are different works, the first a large epic novel, redacted in realistic and documentary style (having an autobioraphical source), still with frequent incursions in mithic, the second a fantastic tale, but they have in common the treatement of o war episode, the american bombings in Bucharest in 1944, and especially the first one of them, occured on the Easter Sunday. Those bombings had reverberations also in others Romanians writters such contemporary Gabriel Stan, who described in his The 5th Mosquetaire the bombings of Braşov, in central Romania.
\end{abstract}

Keywords: literature, war, Mircea Eliade, The Forbidden Forest, Twelve Thousand Head of Cattle, Gabriel Stan. 
El presente trabajo intenta realizar un nuevo enfoque sobre dos obras del gran escritor rumano Mircea Eliade, la novela épica La noche de San Juan y el relato fantástico Doce mil cabezas de ganado, al estudiar el tema de la guerra, que, pese a encontrarse tan presente en ambas, ha sido menos puesto de relieve hasta ahora. Son obras muy diferentes, por un lado una novela de grandes dimensiones redactada en estilo realista, en cierta medida un fresco de la sociedad rumana de la guerra y del advenimento del comunismo, y por otro un relato de apenas unas páginas que sorprende un momento de la Segunda Guerra Mundial en clave fantástica. Lo que los une es uno de los temas tratados, el del bombardeo americano sobre la capital rumana, acontecido el Domingo de Pascua de Resurección del año 1944, que recayó en el cuatro de abril, en el 4 del 4.

El mayor peso se lo lleva, como es normal, la novela, la única de este tipo en la obra eliadesca, y, según la crítica positiva, una de las más importantes de la literatura rumana, incluso la más importante según el indianista Sergiu Al. George, quien la considera el primer caso de novela total en la literatura rumana: fresco histórico, novela política, sentimental, intelectual, costumbrista y, sobre todo, mítica. Pero hay otros críticos, como Alexandru Paleologu, quien dice que la novela no representa «un logro épico de tipo objetivo», que es «infelizmente titulada y sufre de desigualdades y larguezas» (1988: 23).

El tema de la guerra es introducido de forma paulatina en el hilo narrativo, para volverse omnipresente en los dos tercios finales. De hecho, la primera alusión a la guerra no aparece sino en el último párrafo del sexto capítulo:

Bajó algo más tranquilo al comedor. Al lado del cubierto lo esperaba el correo; el último número de «Farul nostru» y una carta de Viziru. Le decía que intentaría verlo a principios de abril, antes de irse a Londres. ¡Hay guerra! Se acordó de repente Biriş. ¿Qué estará buscando en Londres? (Eliade 1998: 214)

La segunda aparece dos páginas después, en el marco de una conversación sobre un presunto cuadro de Rubens, propiedad de un personaje muy interesante, el profesor Antim. Intenta este enviarlo mediante Ştefan Viziru, el protagonista, a Londres, para enseñárselo a un experto e intentar valorarlo. Le pide transportarlo ya que para él es más sencillo, al ser enviado en misión diplomática; tiene que pedirle este favor porque los sucesos se van precipitando: los alemanes han desembarcado ya en Noruega y los días siguientes podrían empezar los combates en el frente francés. Pero también se precipita la accion de la novela, pues Viziru lo rehusa, pero el diálogo entre ellos sigue en Londres, saltándose Eliade el espacio-tiempo sin ningún aviso, sin ningún artificio, sin nada, despistando al lector. El profesor, esta vez en su faceta de coleccionista y marchante de obras de arte, está acompañado por su sobrino, Spiridon Vădrastra, quien presume una y otra vez de sus relaciones en el ministerio, lo que le había valido la rápida obtención del visado y de los billetes de avión, además de una suma de dinero, puesto que habían salido ambos en misión diplomática. Pero la conversación en la Embajada rumana de Londres se va deslizando hacia la situación de los bombardeos alemanes sobre la capital británica; ahí hay más gente y alguien de al lado dice que ya han conseguido arrebatar una centena de aviones alemanes. 
Se siguen contando a continuación, de manera muy documentada, distintos sucesos relacionados con la Legación Rumana en Londres y con esos personajes; se nos habla de un "acuerdo económico firmado en plena campaña de Francia» (Eliade 1998: 219) a la vez que van llegando noticias sobre el ultimatum soviético a Rumania; debe entregar esta, en un plazo de tres días, la provincia de Besarabia. Las relaciones entre el Reino Unido y Rumania se van enfriando y el profesor Antim es arrestado, al volverse sospechoso. «Estamos en guerra» explica el protagonista, «se habrá hecho una confusión» (Eliade 1998: 220).

El ambiente de rumores de una guerra no muy cercana deja paso en este momento a una intromisión de esta en la vida de los personajes; a partir de ahora no se habla más que de bombardeos y de refugios, de cañones anti-aéreos y de muerte. Es interesante seguir el destino del profesor Antim, que no se separa en ningún momento de su cuadro, metido en una carpeta. Lo había autentificado y había encontrado a un cliente, pero se dio cuenta de que no podía hacer nada con el dinero, ya que guardarlo encima no convenía y si lo depositaba en un banco «ahí se quedaba», están todos a la espera de que se bloqueen las cuentas. Ahí, en Londres, se siente más a salvo, pese a los bombardeos, con el tesoro que lleva encima no puede irse al campo... Se lo explica a Ştefan mientras se están oyendo las baterías del Hyde Park.

En este ambiente de continuos bombardeos y de bajadas y subidas hacia y desde refugios van llegando noticias de la desastrosa situación de Rumania, a la que Hitler y Mussolini obligan a entregar a Hungría, por el Dictado de Viena, la mitad de Transilvania. La palabra «guerra» se vuelve omnipresente, obsesiva, está en boca de todos los personajes que aparecen y desaparecen en un continuo vaivén.

El profesor experimenta una degradación muy acelerada, tiene cada vez más la seguridad de que «les quedarán los huesos por ahí», a la vez que se arruga en torno al cuadro al que no suelta en ningún momento, ni siquiera para ir al cuarto de baño. Pero todo es fragmentado por los ataques aéreos, están continuamente pendientes de las alarmas. A un momento dado, el profesor dice que «las noches se hacen cada vez más largas. Y mientras dura la alarma, la noche me parece infinita...» (Eliade 1998: 229). Ya en la calle, se oye nuevamente la alarma y tienen que entrar en un refugio algo lejano de la casa; tras salir Antim se duerme respaldado en un muro pero es despertado por las salvas de la artillería antiaérea y tienen que bajar otra vez al refugio que será fuertemente sacudido por una muy cercana explosión. Al ambiente, que es totalmente apocalíptico, Eliade le da un toque de cinismo cuando vuelve a referirse a la valiosa carpeta con el cuadro de Rubens, que Vădrastra devuelve a un Antim espantado de no perderla.

El capítulo sigue describiendo la vida del personal de la legación rumana de Londres durante los bombardeos del otoño de 1940, con una exacta cronología de los sucesos. Con gran maestría y con una precisión documental se nos cuenta el incruento bombardeo del día 9 de septiembre (9 del 9$)$, bombardeo que fue vivido por el propio autor ${ }^{1}$.

${ }^{1}$ Mircea Eliade fue enviado el día 10 de abril de 1940 en misión diplomática (como agregado de prensa) a la Legación Rumana de Londres, sin saber que era el comienzo de un exilio que no acabaría nunca. El día 9 de septiembre vive el atroz bombardeo sobre la capital británica desde la cual se entera de los dramáticos y trágicos acontecimientos que arrasan su país. 
Así, el 9 de septiembre Ştefan fue invitado a comer por el secretario de prensa, al que encuentra jugando póquer con otros rumanos. «Estamos jugando desde las cinco» (cada uno busca su propia vía de evasión), le comenta este, «para olvidarnos de los problemas. Pues si nos consumáramos por cada catástrofe, nos volveríamos locos...». Y le pregunta qué piensa hacer, quedarse en Londres o irse a la campiña ante la posibilidad de una invasión y de bombardeos masivos. Viziru le contesta que su método de fugarse es el de quedarse aislado unas horas cada día, sin tener ningún contacto con los sucesos; durante aquellas horas anístoricas es libre, evadido del espacio-tiempo cuyo

dueño es hoy la Guerra. Ella ha confiscado toda la historia contemporánea, el tiempo en el que nos ha tocado vivir. Toda Europa está viviendo un monstruoso autómata, puesto en marcha por las noticias lanzadas cada minuto por las centenas de emisoras de radio, por las ediciones especiales de los periódicos, por las conversaciones entre amigos... Hasta al quedarnos solos, seguimos pensando en la guerra, seguimos siendo los esclavos de la Historia. (Eliade 1998: 233)

Y el protagonista continúa haciendo unas consideraciones muy interesantes sobre la muerte y la libertad, así como sobre la salida del Tiempo histórico y la entrada en otro tiempo. El terror de la guerra y de la destrucción, considera, es mucho mayor para ellos, para los que asisten de forma pasiva a los bombardeos que para los militares ingleses quienes están defendiendo de forma activa a su patria. Porque ellos pueden morir en cada instante, y «morir sin gloria, cual hormigas aplastadas, cual ratones atrapados, mojados con gas y quemados vivos» (Eliade 1998: 234). La única manera de morir libre y no como esclavo es evadirse del terror de la Historia, al rehusar ser confiscado y terrorizado por el destino. De hecho, la idea de la proyección en otro Tiempo, en un Más Allá a través de la Imaginación es una de las ideas principales no solo de esta novela sino de toda la obra eliadesca. El crítico Radu Florian cree al respecto que «los individuos pueden sobrevivir a la fuerza destructiva de la historia si pueden hacer caso omiso de ella, si mediante su subjetivismo consiguen dar un significado transhistórico al flujo de los acontecimientos» (1984: 137) pero, contraargumenta que semejante filosofía no puede ser una fuente de resistencia real ante la historia ${ }^{2}$.

Y es verdad, justo en el momento de acabar con estas consideraciones se vuelve a oír el chillido de la sirena, lo que los hace renunciar finalmente al póquer para bajar al sótano que sirve de refugio, visto que unas explosiones extremadamente cercanas sacuden el edificio. Lo hacen cuando «las ventanas se ponen a temblar», la mesita con naipes se viene abajo dispersándose las fichas, y «están justo encima de ellos». Eliade describe de esta forma maestra el peor bombardeo sobre Londres; a un momento dado alguien que había salido del refugio vuelve con la noticia, son

${ }^{2}$ R. Florian expone que el problema planteado no es el de justificar el terror de la historia, tal como, según Eliade, estarían haciendo las principales filosofías historistas, el hegelianismo y el marxismo, sino de proceder de tal forma para que la historia ya no sea un terror. 
solo dos palabras que lo dicen todo: «Arde Londra!» («iLondres está ardiendo!»): «Hacia la City, el cielo estaba incendiado. Llamaradas rojas estallaban periódicamente de aquella masa ensangrentada, alzándose ahora con gran ímpetu, ahora debilitándose, para volver a estallar con más y más fuerza» (Eliade 1998: 237).

El protagonista consigue escaparse de esos momentos tan trágicos mediante los recuerdos de momentos felices, pero al levantar lentamente la cabeza, «se encontró el cielo entero recorrido por reflectores [...]. Rafagaban intermitentemente los cañones antiaéreos; enmudecían de repente, como si se hubieran preparado para escuchar, luego estallaban otra vez, en salvas irregulares» (Eliade 1998: 241).

La muerte de Vădrastra, víctima del cuadro que lo llevó bajo las bombas de Londres, es el primero de los fines trágicos de los personajes de esta novela. Irán desapareciendo uno tras otro, hasta el final, cuando muere el mismo protagonista, tras la muerte de su doble, Ciru Partenie. El segundo en hacerlo es el mismo profesor Antim, pues en realidad no había muerto aquella noche; se vuelve a encontrar con Viziru en la Legación y ese le devuelve el cuadro que había pasado por tantas peripecias. Fallece por un infarto mientras esperaba sentado en un banco de la estación de Paddington el tren que lo llevase a la ciudad de Oxford, más segura ${ }^{3}$. Él había sido un gran coleccionista de obras de arte que heredan su hija y su yerno, un profesor en gran medida caricatura suya, a quien Eliade le da un nombre rídiculo, de pueblerino (Gheorghe Vasile). Este irá vendiendo los valiosos objetos uno tras otro, a fin de comprar todos los ejemplares de la popular «Biblioteca para todos» y llevarlos a su pueblo para crear una Fundación Cultural que lleve su nombre.

Pero de momento la acción de la novela sigue en Londres, y Eliade presenta de forma magistral «el terror de la historia», los grandes destrozos y el pánico creado: al llegar Viziru delante del edificio de la Legación Rumana observa cómo los cristales de las ventanas se habían roto y por Cromwell Road algunas casas habían sido incendiadas; la última planta del Museo de Ciencias Naturales estaba todavía ardiendo.

Él tiene que ir a Lisboa, hay por fin plaza y coge el tren para Bristol, donde llega de noche y se percata de que la estación había sido bombardeada y de que era muy difícil encontrar un taxi que le llevara las dos maletas hasta el hotel. En la oscuridad, la ciudad le pareció siniestra, con «esqueletos de casas a ambos lados de la calle». En la recepción del hotel le confirman que en Rumania la situación era muy confusa, puesto que la Guardia de Hierro se había levantado en contra del jefe del gobierno, el general Antonescu. Eliade describe esta rebelión «legionaria» y la muy dura respuesta de Antonescu en el subcapítulo siguiente, al saltar la acción, tras el embarque de Ştefan en el vuelo a Lisboa, desde Londres a Bucarest. Aparecen en este final de la primera parte y en la segunda unos personajes secundarios, el ermitaño Anisie, Ciru Partenie (un doble del protagonista e implícitamente del autor), Mişu Weissman, Biriş, Bibicescu, Gheorghe Vasile, el teniente coronel Băleanu,

3 Tras el atroz bombardeo del 9 de septiembre de 1944 sobre Londres, Eliade se retira a Oxford, igual que su alter ego Viziru; al comienzo del año 1941 es nombrado consejero cultural en Lisboa. Su salida del Reino Unido coincide con el cese de las relaciones diplomáticas con Rumania, motivo por el cual soporta un tratamiento degradante por parte de los aduaneros británicos. 
Bologa, Bursuc, Ioana, Irina, Catalina, la señora Ivascu, en torno a los cuales se oyen voces y tumulto de multitudes congregadas en calles y plazas así como disparos: los hebreos son cazados y matados «cual fieras» por los «legionarios» de la Guardia de Hierro y el ejército dispara contra los «legionarios». La emisora de radio está en manos de los legionarios y anuncia todo tipo de hechos; hay combates por todo el centro, especialmente cerca de «Grădina Icoanei» («El Jardín del Icono»); parece ser que hay agentes provocadores que disparan desde las casas hacia la multitud. La situación es muy bien presentada por Biriş, un amigo del protagonista:

Los legionarios se han rebelado en contra del general Antonescu, con quien estaban gobernando el país desde hacía cinco meses y quieren tumbarlo. El ejército está al lado del general Antonescu y desde hace dos días está disparando en los legionarios. Y los legionarios disparan sobre quien sea: Misu, yo, puede que hasta sobre ti... (Eliade 1998: 264)

La rebelión fue sofocada el día siguiente y en el acto empezaron las represalias: detenciones masivas de legionarios, juicios rápidos ante tribunales militares, cordones de gendarmes por las calles controlando a los transeúntes. El tema de la guerra vuelve una y otra vez a los labios de estos personajes de interesante tipología que van desapareciendo de la novela, igual que Vădrastra o el profesor Antim, mediante una muerte trágica. La más «aparatosa» es, desde luego, la de Bibicescu, un dramaturgo fallido, el oportunista que cambia la camisa verde de los legionarios por la roja, comunista, a fin de mantenerse como director de un teatro. Lo es sobre todo por los efectos teatrales y grotescos creados por Eliade, quien se burla del primitivismo de un soldado ruso (mediante cuyo comportamiento es parodiada de forma cínica la guerra) en el momento de llegar la noticia de aquella muerte, un día invernal del comienzo del año 1945. Pero, hasta entonces, sigue la cronología, con la entrada de Rumania en guerra contra la Rusia soviética, los bombardeos aliados de 1944 y el golpe de Estado con el cambio de bando en contra de Alemania, el antiguo aliado, y la subsiguiente ocupación soviética. Viziru vuelve desde Lisboa y parte como voluntario al frente ${ }^{4}$; es por él, cuando viene de permiso, que los demás se enteran de que habían perdido la guerra, y de que se avecinaban tiempos muy sombríos.

Las noticias del frente suelen ser malas (es recordada la derrota de Estalingrado y la muerte de decenas de miles de soldados rumanos, después el avance de los soviéticos hacia las fronteras y el territorio nacional), pero a un momento dado llega también una noticia buena: Viziru, quien llevaba dos años de voluntario en el frente ruso, ha conseguido salvarse junto a su división del cerco y fueron evacuados desde Crimea.

Es, en realidad, solo una aparente buena noticia, puesto que Eliade quiere preparar con ello el acontecimiento colectivo más trágico de la novela, el del incruen-

${ }^{4}$ Aquí el personaje ficticio Viziru se desprende del personaje real, el autor, pues ese se quedó tres años en Lisboa, tras lo cual se fue a París, yendo a Rumania solo una semana en el año 1942. Es posible que Eliade haya tenido la intención de alistarse, para complacer y satisfacer el orgullo de su padre, militar de carrera, y presumir de valentía ante el resto de su familia, y especialmente su hermano, que también fue militar (Tofan 1996: 33, 34, 116). 
to bombardeo americano acontecido el Domingo de Resurección de aquel año 1944, que recayó en el cuatro de abril: «Hacia finales de marzo, la primavera llegó de repente. La pascua recaía el cuatro de abril» (Eliade 1998: 334); «De vez en cuando recibimos también una buena noticia. Ha telegrafiado Viziru. Se salvaron todos de Crimea, pudieron ser evacuados por mar... Ahora están en Constanţa. Llegará el domingo, el día de Pascua» (Eliade 1998: 335).

Aquel acontecimiento tan minuciosamente prepararado será presentado en todo su terror, tras una breve introducción que no lo hace presagiar:

Aquella mañana, Irina iba por las calles con paso apurado, teniendo prisa, como si se hubiera retrasado en un encuentro. Pero andaba sin mirar por donde iba, torciendo al azar por las calles, mirando para abajo, con los ojos medio cerrados, como si le hubiera costado no dormirse. Tropezaba continuamente con grupos de gentes parlaquinas, casi alegres, pues era un día claro de primavera, con el cielo azul, inesperadamente sereno. Se despertaba a ratos frente a alguna iglesia y entonces ralentizaba el paso, observando por unos instantes a los niños jugueteando en sus ropas de Pascua sobre los escalones. Luego seguía, con más prisa todavía. (Eliade 1998: 338)

Es el ruido de la sirena el que la hace parar y el que rompe el orden. Un señor le dice sonriendo que no se asuste, que son ejercicios de defensa antiaérea, lo dijeron hasta por la radio. El ambiente general es de mucha confusión, la gente está como indecisa, como sin saber si tomárselo en serio, mientras los sargentos pitan continuamente y grupos de niños van corriendo ruidosos por las acera. «Luego, a la vez, estallando como de todas partes, se oyeron los cañones antiaéreos» (Eliade 1998: 338) e Irina levantó la mirada hacia arriba:

El cielo era igual de azul. Lo único era que había empezado a teñirse de nubecillas blanquecinas, muy menudas, cual una erupción, que surgían como de la nada y se disipaban rápidamente. Al mirar con más atención avistó, muy arriba, como un relucimiento metálico, luego otro, hasta que, tras pestañear continuamente para aclarar su vista, descubrió a toda la escadrilla, volando en orden, sin prisa, como si de un desfile se hubiera tratado. (Eliade 1998: 338)

Se refugia en una iglesia que estaba casi vacía, pero justo después van entrando más gentes, pálidas, asustadas, que se arrodillan delante de los iconos, pidiéndole al cura que los bendiga, y en ese momento unas explosiones muy cercanas hacen que se tambalee el edificio, rompiéndose los cristales de algunas vidrieras.

Al salir de la iglesia, tras el cese de la alarma, tropieza con los escombros que hay en los escalones y se percata de que el cielo se había oscurecido, de que el sol había cambiado de color, volviéndose rojizo, y se escondía detrás de una cortina de humo y polvo. Un rumor de voces espantadas, cortado por gritos sordos, venía de todas partes, mientras una mujer, corriendo sin mirarla, gritaba que no había agua.

Poco a poco van llegando las noticias: destrozaron la Estación del Norte, bombardearon los Talleres de los ferrocarriles, destruyeron, ...destrozaron,... La Calle de la Victoria está ardiendo,... Los americanos, ... bombardearon los depósitos de agua... el mismo Día de Pascua... Sin darse cuenta, se puso a correr encontrando a 
su paso «coches, taxis, camiones que corrían como mareados por el humo, tratando de sortear las calles bombardeadas, dirigiéndose hacia los bulevares» (Eliade 1998: 340). El final del párrafo es totalmente apocalíptico:

En la esquina, lo comprendió de repente. En el lugar donde había estado la casa de Ioana, así como muchas otras casas del alrededor, había ahora unas colinas humeantes de ladrillos y escombros, que se revertían hasta en medio de la calle. Grupos de gentes subían y bajaban sobre las ruinas, titubeantes, cegados por el polvo, tropezando en hierros y leños, llamándose continuamente y cubriéndose después las bocas con las palmas, alzando por momentos los dos brazos, ensangrentados, hacia el cielo. (Eliade 1998: 341)

En esta segunda parte de la novela serán descritos también otros sucesos de la guerra, pero el punto central desde nuestra perspectiva es ese tan fatídico Domingo de Pascua del 4 del 4 del 44, día del primer bombardeo americano. A este bombardeo se refiere el autor en otra de sus obras, el relato Doce mil cabezas de ganado, tratándolo aquí en una clave diferente, de corte fantástico. Así, el protagonista, un tal Iancu Gore, hombre de negocios, experimenta un regreso temporal, es trasladado a otra dimensión y el detonante de ese traslado es el estridente ruido de la sirena antiaérea que oye yendo por la calle, tras salir de un restaurante. Corre para ponerse a salvo del bombardeo que ya no pensaba que acontecería, pues habían pasado las doce horas, y en el refugio asiste a una conversación llevada por tres personajes, un señor mayor y dos señoras (vuelve el tema del ejercicio aéreo, de que el bombardeo no era más que una simulación pues así lo habían dicho el día anterior por la radio), que habían muerto cuarenta días antes, durante el bombardeo de aquel fatídico Domingo de Pascua. Habían fallecido en el mismo refugio que él abandona a un momento dado para regresar al restaurante en donde varias personas le confirman que no había habido ningún bombardeo momentos antes; para convencerlo lo llevan al lugar del refugio que estaba cubierto con escombros desde hacía ya tiempo, igual que la zona del alrededor. A pesar del experimento vivido, Iancu Gore, personaje profano por excelencia, «no observa las discontinuidades de la existencia, su creencia es que todo tiene una lógica y un determinismo» (Simion 1981: 622), sufre como de una amnesis.

Está claro que los bombardeos aliados del 04/04/1944 y posteriores han marcado profundamente a Mircea Eliade, igual que han marcado a toda su generación; reflejos de aquella tragedia colectiva sigue habiendo en la literatura actual rumana pues los recuerdos, transmitidos por vía oral o escrita continúan ahí, sesenta años después de acabada la guerra. Uno de los libros en el que es tratado ese acontecimiento es El Quinto Mosquetero del escritor brasoviano Gabriel Stan, quien describe con suma maestría los bombardeos que hubo sobre su ciudad, Braşov, en el centro del país, recordando la muy conocida leyenda local de la muerte colectiva acontecida en el mayor refugio de la ciudad, sito en los sótanos del palacete Kertch, construido sobre las antiguas murallas medievales y demolido después a causa de los muy graves destrozos sufridos. Existe en aquel pasaje cierta similitud con la descripción de Eliade, pues la protagonista del episodio es también una mujer (más joven) que entra (acompañada de una amiga) en una iglesia, la Iglesia Católica de la actual calle Mureşenilor, en el casco antiguo: 
El primer bombardeo pasó justo el día de Pascua. Se había anunciado que vienen los americanos con 'huevos rojos'. Llevaba un traje nuevo, como se solía llevar en Pascua. [...] Entraron en la Iglesia Católica de la calle 7 de noviembre y, cuando salieron, todo el mundo miraba para arriba. Pasaban los aviones uno tras otro, bum-bum-bum... [...] Fue entonces cuando se oyeron las sirenas, cuando los aviones ya estaban encima. Oyó como caían las bombas. [...] Frente al palacete Kertsch paró un camión lleno con oficiales del Ejército del Aire. Entraron en el sótano del edificio y ahí encontraron su fin. [...] Al salir, tras ablandarse los bombardeos, después de que hubieran bombardeado también la antigua estación, había un humo como si hubiera niebla. (Stan 2012: 126)

Es una descripción exacta, de tipo documental, similar a la empleada por Eliade para describir los bombardeos de Londres o de Bucarest en su obra maestra La Noche de San Juan, la obra literaria fundamental que ha servido de base en la redacción del presente trabajo; una obra con bastantes tintes autobiográficos (véanse Fragments d'un journal, Gallimard, 1973) pero, igual que el resto de su creación, llena de signos y símbolos, feliz resultado del encuentro entre «una imaginación productiva y una profunda erudición» (Simion 1986: 279). Obra que tiene un doble fin: prolongar en una existencia profana los sucesos narrados por los mitos y defender al individuo de lo que el autor llama el terror de la Historia, un terror ejercitado sobre los humanos por la historia y por un mundo en el cual Dios parece haber muerto.

\section{Referencias bibliográficas}

ELIADE, Mircea (1973): Fragments d'un journal. Paris: Gallimard.

- (1981): In curte la Dionis. Bucarest: Cartea Românească.

- (1998): Noaptea de Sânziene. Bucarest: Univers Enciclopedic.

Paleologu, Alexandru (1988): «Încercarea înţelegerii». Caiete Critice, núm. 1-2: 23.

RADU, Florian (1984): Dialog cu secolul nostru. Bucarest: Editura politică.

Simion, Eugen (1986): Timpul trăirii-timpul mărturisirii. Bucureşti: Ed. Cartea Românească.

STAN, Gabriel (2012): Al V-lea muşchetar. Braşov: Ed. KronArt.

TofAn, Sergiu (1996): Mircea Eliade. Destinul unei profeţii. Galaţi: Ed. Alter Ego Cristian\&ALGORITHM. 